Commentary

Open Access

John Tyler*

\title{
A Commentary on David Hammack's Policy for Nonprofit Organizations: The Values Dilemma
}

DOI 10.1515/npf-2015-0035

In his article Policy for Nonprofit Organizations: The Values Dilemma, Professor David Hammack asserts that effective policies are needed for the nonprofit sector that "reconcile equality with liberty," as if these principles are inherently incompatible. The article presents ways in which liberty was exercised to shape preferred values (e.g., religious freedom) but also allowed institutions to intentionally or unintentionally channel different groups into unequal opportunities - thus juxtaposing liberty and equality. The article continues that such channeling has reinforced choices that entrench a status quo that perpetuates rather than alleviates discrimination and inequality.

As the article ponders possible policy approaches to the proposed values dilemma, it challenges solutions that rely too much on quantitative, economic analyses that neglect qualitative value. It also asks who properly should undertake the reconciliation - government, "experts," individuals, communities, institutions, or others - before finally seeing roles for each or all. It then finds challenges with uniform standards and their historical outcomes of both bridging/narrowing gaps while also imposing/expanding divisions that worsen it.

Ultimately, the article lamentingly concludes that there is not a "simple" or "single" resolution in part because the U.S. has made adoption of one "difficult." The article then suggests that discussions about policy for the sector would be "more sophisticated, and more useful" if they incorporated "relevant historical analysis of institutional patterns."

In short, the article's conclusions have merit, but its shaping of the "values dilemma" is dangerous. This commentary addresses these in reverse order.

*Corresponding author: John Tyler, Ewing Marion Kauffman Foundation - Lgal, Kansas City, Missouri, USA, E-mail: jtyler@kauffman.org 


\section{Challenging the Framing of "The Values Dilemma" to be Reconciled}

The posited "values dilemma" is faulty for at least two reasons: lack of definitional clarity and its grounding in a false dichotomy.

The article does not define "equality" or even give a meaningful sense of context for the term. We must guess whether it applies to talents and abilities, economic resources and material possessions, recourse to law, participation in political processes, opportunity to pursue potential, some combination of these, or something else entirely. We also are left wondering whether "inequality" is a synonym for "inequity," if the latter is a subset of the former, or if it is something else entirely. This ambiguity prevents a consistent understanding of the proposed dilemma, which then precludes reasonable debate about its nature or potential approaches to resolving or mitigating those effects that might arise.

A second and more substantive fallacy is that the posited dilemma positions liberty and equality as if they are polar opposites or on a collision course. Setting aside the need for definition, the Declaration of Independence synthesizes an extraordinary body of thinking that characterizes humanity as being created equal and endowed - not vested or authorized, but "endowed" - with "unalienable" rights to life, liberty and pursuit of happiness. Thus, liberty and equality are regarded as co-equals and perhaps interdependent (but not inversely so) such that a question arises whether equality can be achieved, or even aspired to, without life, liberty, and the pursuit of happiness.

If that is the case, then "reconciling" the proposed dilemma, whether specific to policy for the nonprofit sector or more broadly, presumes sacrificing liberty, which paradoxically then jeopardizes equality - the very end being pursued. In terms of "reconciliation," history suggests that less equality will not generate more liberty, nor less liberty more equality; but less liberty inevitably does and will diminish equality in its most meaningful senses just as less such equality diminishes liberty.

Thus, because liberty and equality are complementary, likely intertwined, and certainly not in conflict, positing the dilemma as a base for deriving policy threatens damaging consequences for the sector's applications and for society more broadly as efforts to lessen liberty in order to expand equality cannot be constrained to the nonprofit sector. 


\section{Beware Neglecting Historical Experience and Pursuing Simple, Single Solutions}

The article rightly admonishes against neglecting the lessons of history. After all, our time and circumstances do not exist in an epochal vacuum. Understanding history and incorporating its lessons as the article encourages can inform our individual and collective decisions with lessons from the past - good and bad, if we so choose. Doing so also reminds us that today's discussions result in tomorrow's decisions, actions, and effects that become the next day's consequences and history, including lessons for then if desired.

History's lessons validate the article's conclusion that there is not - and should not be - a legitimate simple or single policy resolution to the nonprofit sector's shortcomings. Rather than lamenting that conclusion, however, it might be best to embrace it as an opportunity to better inform policy, enhance awareness of the existence of inequality and inequity and their causes, and strengthen continuing efforts for deploying the sector to address those problems.

Moreover, the strengths and character of how the sector is used, resulting contributions to civil society, and the diversity of its applications all belie simple, single policy solutions. The sector's usefulness emerged over time in the American tradition as complex, multi-faceted, economically important, and especially tolerant of apparent inconsistencies and incongruities. It serves unique - sometimes conflicting, sometimes overlapping - economic, social, and political roles and responsibilities that depend on its ultimate (but not absolute) distinctiveness from business and independence from government. Certainly not least of all, the sector also exemplifies our nation's core, genetic principles in action, among them First Amendment freedoms of speech, assembly, religion, and petition, as the article recognizes.

Simple, single "resolutions" that I am aware of do more to undermine these traits than enhance them. They tend to unduly denigrate the healthy pluralism of ideas and variety of responses, inhibit little known or even unpopular perspectives and activities, and interfere with community and individual initiative to identify and creatively address problems, even if risky and ultimately unsuccessful. Presumably, these qualities remain at least relevant if not indispensable, and their surrender would be tragic, especially if by accident or incidental to singular-minded, one-dimensional thinking.

Among the consequences might be extensively politicized uses of the sector subservient to preferences and patronage from those in political power at a given moment. Absent principled boundaries and vigilance, that power more 
likely than not entrenches its interests and imposes barriers to or prevents emergence of other interests, thus preserving its preferred status quo, which the article warns against. At best, such exercises of power not only are unlikely to solve for problems of inequality but they ironically risk exacerbating them and the very concerns purportedly being addressed.

Even though, as the article points out, certain historic and current applications of the sector's roles, responsibilities, and principles have contributed to separateness, inequality, and inequity, numerous other applications of the liberty that enables the sector's uses have sought (and successfully fought) for the opposite. To eliminate the former applications risks damaging or even precluding the latter's efforts and successes.

Among the simple, single resolutions are those that over-emphasize tax policy solutions for what are fundamentally non-tax matters. One frequently mentioned aspect of those solutions seeks to bestow "worthiness" only on those nonprofit organizations that contribute economic value at least commensurate with their tax benefits, potentially favoring profitable arts and culture organizations and disfavoring food pantries and homeless shelters. In addition to overvaluing quantitative and under-appreciating qualitative contributions, which the article also rightly cautions against, tax-based standards inevitably inject government into assessing whether given organizations and the sector's usefulness as a whole are "adequate," thereby generally politicizing the sector's uses and users, rendering them dependent on government, and undoing one of the sector's core distinguishing characteristics ${ }^{1}$ - not to mention the First Amendment's framework by which our government is not to interfere with such matters in the first place.

This is not to suggest that there should not be standards, regulations, and enforcement. Abuses have occurred and will occur. Our governments have legitimate roles in protecting integrity, helping root out corruption, fraud, and abuse, and even preserving contrarianism. However, that is a far cry from responsibility for condemning good faith mistakes, unfortunate timing, and even bad ideas that might give rise to an economic "loss" vis a vis tax-favored

1 This observation is based on tax treatment rather than direct contracting and grantmaking where government has affirmative duties to assess the quantitative and qualitative worthiness of recipients and their outcomes. However, over-reliance on government grants and contracts is sector-agnostic as both the business and nonprofit sectors and their member enterprises lose independence from government from their respective degrees of dependence on such grants and contracts. Ultimately and when experienced at extreme levels, such dependence can threaten the integrity of our political/Political system itself. 
treatment - all of which could follow from using tax policy as a base for setting standards for assessing performance, outcomes or impact.

This also is not to suggest that all is right and equitable in America or with the nonprofit sector's uses, but its uses are much more likely to be integral to the solutions than to fomenting the problems, although Prof. Hammack rightly cautions against naively believing that the sector's actual and potential uses are beyond reproach.

History bountifully provides examples of harmful, even disastrous, outcomes from erroneously framed problems. Historical experience and current practice evidence success in deploying the sector's complexity and heterogeneity. They also demonstrate the essential place of liberty, not in battle with equality and needing to be reconciled with it but as a necessary armament along with justice as allies pursuing the most valuable notions of equality, overcoming inequity, and striving for all to pursue happiness and enjoy the blessings of liberty - both in aspiration and in reality.

Note: John Tyler is the General Counsel and Secretary for the Ewing Marion Kauffman Foundation. He has published numerous scholarly works and speaks frequently on civil society and philanthropy. In addition to appreciating his conversations with Prof. Hammack at the symposium and otherwise, John also is grateful for suggestions on drafts of this commentary from Joanne Florino, Les Lenkowsky, Sue Santa, and Dane Stangler, many of which were incorporated but all of which were appreciated. 